\title{
National Atlases - an atlas type reconsidered
}

\author{
Eric H. Losang ${ }^{a}$ \\ ${ }^{a}$ Leibniz Institute for Regional Geography, Leipzig
}

Keywords: Atlas, National Atlas, Atlas-Analysis, Methodology

\begin{abstract}
:
The publication of the first National Atlas in 1899 marked the emergence of an atlas category that thrived over the upcoming century. The "Atlas de Finlande", successfully presented at the Paris World Exhibition in 1900, used to coin this title and being published in Paris by the National Geographic Society of Finland, had a true nation-building function.

In the same year, following the US victory in the Spanish-American War, the Atlas of the Philippine Islands (Atlas de Filipinas) was published by the US Coastal and Geodetic Survey, containing two front pages, one in English indicating the USC\&GS as publisher, the other in Spanish mentioning the supervision of the project by Father J. Algue, the director of the Manila Observatory. Never referred to as a national atlas, it comprises a series of maps on the Islands and a bilingual abstract on map conventions, a bilingual gazetteer and a thorough introduction into places, places names and their pronunciation. For these atlases, the publication circumstances remain somehow heterogeneous and cannot be compared with modern national atlases and even atlases published in the same period seem to have different hallmarks.

Why considering the Atlas de Finlande a national atlas but define the 1878 Statistical Atlas of the United States only a statistical Atlas? Because of the title? What atlases are more nationally defined than school atlases? Is an atlas published by a non-governmental executing agency a national atlas? Is governmental support and approval needed?

How national atlases fit into different approaches to thoroughly define them (e.g. Salischew 1967) has been subject to academic cartographic self-conception that ignored technological, institutional, economic and user-related developments over time. In addition, these approaches to categorise atlases solely focused structural elements, such as the number and topics of maps and their temporal and spatial sequence. The question of how atlases have been characterised by their publishers and have been perceived in closely following reviews is a possible approach to either situate national atlases as a strict category or a politically induced perception.

The article introduces a post-structuralist approach focussing the textual analysis of both, self-perception verbalized through introductions and prefaces in respective atlases and reviews, contemporarily published in the following years. Introducing common definitions and juxtapose the historical perception of national atlases tries to operationalize Harley's critical approach, that situates maps in their respective historical context. By regarding an atlas not only as a bound collection of maps but as a carefully organised selection of spatial information unveils the power of atlases, which maybe exceeds those of single maps. To analyse atlases in their historic context by including their self-definition and contemporary perception will identify so far unattended aspects and to alternative views on national atlases and their editing and production frameworks. Thus retrograde definitions can be reconsidered.
\end{abstract}

